\title{
Development of Discrete Flow Paths in Unsaturated Fractures at Yucca Mountain
}

\author{
G. S. Bodvarsson *, Yu-Shu Wu, and Keni Zhang \\ Lawrence Berkeley National Laboratory, Earth Sciences Division, \\ 1 Cyclotron Road, MS 90-1116, Berkeley, CA 94720, USA
}

\begin{abstract}
We have carried out numerical modeling studies to investigate the development of discretefracture flow paths and flow-focusing phenomena in the unsaturated rock of the potential repository horizon at Yucca Mountain, Nevada. These studies are based on two- and threedimensional (2-D and 3-D) numerical models using site-specific parameters. The 2-D and 3-D models use high-resolution spatial discretization to explicitly include effects of discrete fractures with stochastically developed fracture permeabilities and a continuum approach. The permeability field is generated based on air-permeability measurements at various scales. For most of the cases considered, uniform infiltration with different average rates ( 1 to $500 \mathrm{~mm} / \mathrm{yr}$ ) is prescribed at the top of the model, while variability in outflow at the bottom of the model is used to evaluate the degree of flow focusing. In addition, scenarios involving nonuniform infiltration at the top boundary, different permeability correlation lengths, and different flow-allocation schemes were analyzed. The modeling results obtained from all of the cases showed a remarkably similar flow-focusing pattern at the repository horizon. Furthermore, tracer transport simulation results also revealed additional features of focused flow and transport through the fracture network.
\end{abstract}

\footnotetext{
${ }^{*}$ Corresponding author. Fax: +1-510-486-6115; e-mail: GSBodvarsson@lbl.gov
} 
Key Words: Preferential flow, flow focusing, discrete flow paths, unsaturated flow and transport, fractured media.

\section{Introduction}

Even with significant progress made in vadose zone hydrology in the past few decades, preferential and discrete flow features associated with fluid flow and transport processes in unsaturated fractured rock are currently poorly understood (Pruess et al., 1999a). For example, elevated levels of ${ }^{36} \mathrm{Cl}$ originating from atmospheric nuclear tests conducted in the 1950 s and 1960s were found at several locations in an underground tunnel at Yucca Mountain (FabrykaMartin et al., 1996), suggesting that preferential flow pathways may exist in the unsaturated rock of the mountain. Flow focusing along these preferential paths or well-connected fracture networks may play an important role in controlling distribution of percolation fluxes through highly fractured tuffs (such as in the Topopah Spring welded tuff (TSw) unit, which will potentially house the repository drifts). Phenomena with flow focusing and discrete flowpaths in the TSw unit are thus considered to be of significant importance to potential repository performance (Pruess, 1999).

The mechanism that controls unsaturated flow and transport in fractured rocks is likely to be site-specific and is difficult to characterize for any given site. Nevertheless detailed knowledge of unsaturated zone (UZ) flow and transport processes and mechanisms are needed to accurately predict the degree of preferential flow and transport. In practice, accurate description of flowfocusing processes in unsaturated fractures is essential for prediction of water seepage into emplacement drifts of the potential nuclear waste repository. Recent modeling studies of seepage into drifts showed that the amount of water that bypasses or breaks through a capillary barrier of 
an emplacement drift wall depends not only on the capillarity and permeability of the surrounding fracture system, but also on the heterogeneity of the water flux and flow paths (Birkholzer et al., 1999; Finsterle et al., 2000).

Observations in several laboratory experiments (Su et al., 1999; Geller and Pruess, 1995; and Tokunaga and Wan, 1997) suggest that water flow through unsaturated fractured rock may be discrete and episodic in nature. At the Yucca Mountain site, continual efforts of data collection and analyses have led to formulate a conceptual understanding of the mountain-hydrologic system on large scale (Bodvarsson et al., 2000). Based on the available data, however, it is difficult to understand localized, detailed flow-focusing behavior within the unsaturated fractures because of heterogeneity and significant uncertainties with fracture-matrix properties. Despite the fact that many types of data have been collected across Yucca Mountain, there is currently a lack of field evidence to show whether flow focusing is a dominant mechanism within certain hydrogeological unit. For instance, uniform water potential and matrix liquid saturation data along many layers (Flint, 1998) may suggest that percolation may be very "uniform" in these layer. In contrast, collected elevated levels of ${ }^{36} \mathrm{Cl}$ data along an underground tunnel suggest that there are discrete flow features through fractures. In addition, in spite of extensive tunneling for field studies at Yucca Mountain, only one natural water flow path has been identified (Wang et al., 1998) so far, located at the end of one of the niches excavated in the tunnels.

A range of conceptual models have been proposed for handling water flow in the thick, fractured UZ at Yucca Mountain, from models of continuous fracture flow to those for sparse discrete flow through a very small fraction of the fracture network (Pruess et al., 1999a). In general, modeling approaches for characterizing fracture flow include (1) continuum model, e.g., effective continuum model (ECM) and dual-permeability models (Wu et al., 1999), (2) discrete- 
fracture models (e.g., Rasmussen, 1987; Kwicklis and Healey, 1993; Zimmerman and Bodvarsson, 1996), and (3) models specifically developed to represent discrete geologic features and discrete flow processes (e.g., Finsterle, 2000).

The objective of the work is to investigate the development of flow focusing and discrete paths that may occur through unsaturated fractures within the TSw unit. Modeling of flowfocusing patterns is motivated by the needs of performance analysis on the potential repository, because water percolation in this unit cannot be readily measured at the site and has to be estimated using a model. On the other hand, grid resolution in the site-scale flow model of $\mathrm{Wu}$ et al. (1999) is generally too coarse to capture such small-scale, localized flow phenomena. To quantify flow-focusing behavior, stochastic fracture-continuum models are developed here to incorporate fracture data measured from the welded tuffs and to study flow-allocation mechanisms and patterns. In particular, the models are used to assess the frequency and flux distributions of major water-bearing flow paths from the bottom of the Paintbrush nonwelded (PTn) unit (a unit immediately above the TSw) to the potential repository horizon.

\section{Approach}

The modeling studies of this paper are based on 2-D and 3-D models that have an upper boundary at the bottom of the PTn and a lower boundary at the repository horizon. The 2-D model uses a vertical cross section $100 \mathrm{~m}$ in horizontal extent and $150 \mathrm{~m}$ in vertical extent, which is discretized in a uniform 2-D grid of $\Delta \mathrm{x}=0.25 \mathrm{~m}$ and $\Delta \mathrm{z}=0.5$, resulting in 120,000 gridblocks. The model domain of the 3 -D problem is a $50 \mathrm{~m} \times 50 \mathrm{~m} \times 150 \mathrm{~m}$ parallelepiped, also with the upper boundary at the bottom of the PTn and the lower boundary at the repository horizon. The 3-D model domain is discretized in a uniform 3-D grid of $\Delta x=\Delta y=0.5 \mathrm{~m}$, and $\Delta \mathrm{z}=0.75$, resulting in 2,000,000 gridblocks. 
The dimension of the models was considered sufficient horizontally because the correlation length for variability in fracture permeability and spacing is on the order of $\sim 1 \mathrm{~m}$ (Liu et al., 2000). The $150 \mathrm{~m}$ vertical extent of the model corresponds to an average distance from the interface between the PTn and TSw units to the repository horizon over the repository area. The bottom of the PTn was chosen as the upper boundary because this unit behaves as a porous medium with limited fracture flow. Both uniform and pulse percolation-flux boundary conditions are prescribed at this upper boundary. The side boundaries in the 2-D and 3-D model are treated as no-flux boundaries, whereas the bottom boundary allows for gravitational drainage out of the models.

In this study, the fracture network is modeled as a heterogeneous continuum and flow through the matrix is neglected. This is because the matrix system in the TSw unit has a permeability that is several-orders-of-magnitude lower than that of the fractures. Furthermore, sensitivity studies during this work using a dual-permeability approach conclude that the matrix has little impact on the fracture flow pattern under steady-state flow conditions. Specifying heterogeneous fracture properties in a high-resolution grid is considered adequate to resolve the discrete flow effects expected to occur in the fracture network of the TSw unit. The heterogeneity of the fracturepermeability fields has been identified [in prior modeling studies on seepage into drifts (Finsterle et al., 2000) and elsewhere] as a major factor impacting drift seepage. Multiple realizations of the permeability field were generated to account for the uncertainties in the measured fracture permeability data. The hydrogeologic model parameters of the fracture system are based on those from the site-scale flow model (Ahlers and Liu, 2000). Five different hydrogeological layers (TSw31 to TSw35) exist within the 2-D and 3-D models, each layer exhibiting different fracture properties. 
The spatial distribution of the fracture permeability is prescribed stochastically using the measured air-permeability and calibration data. A spherical semivariogram model with empirical log-permeability semivariograms (Deutsch and Journel, 1992) is employed to generate a 2-D or 3-D spatially distributed fracture-permeability field, mapped to each gridblock. The geostatistical parameters and cumulative distribution function of fracture permeability for the spherical semivariogram model are derived using the measured air-permeability test data (with several hundreds of measurements) for the $\mathrm{TSw}$ unit. Details on generating stochastic fracture permeability and geostatistical plots used for the unit are discussed in Finsterle et al. (2000).

In this work, the van Genuchten function (1980) is used to describe unsaturated flow through the fracture system. The basic fracture properties, other than the spatially varying permeability multiplier, are assumed to be layer-wise constant and listed in Table 1 for the five geological layers. This is because of the lack of meaningful statistical data for the other parameters, such as van Genuchten parameters, as well as the less sensitivity of steady-state flow results to those parameters as compared to fracture permeability. Figure 1 shows examples of the prescribed fracture permeability distributions over the 2-D model domain, using correlation lengths of $1 \mathrm{~m}$ and $3 \mathrm{~m}$, respectively. The figure shows that fracture permeability varies over some four orders of magnitude, from roughly $100 \mathrm{mD}$ to over $100 \mathrm{D}$. The figure clearly shows two different fracture-permeability patterns, with the upper one extending some $-110 \mathrm{~m}$ vertically (the TSw32 and TSw33 units) and the second one extending to the bottom boundary (TSw34 and TSw35). The fracture permeabilities in the upper units (TSw31, TSw32, and TSw33) are generally higher than that of the lower units (TSw34).

The 2-D flow simulations discussed below were carried out using the EOS9 module (Richards' equation) of the TOUGH2 code (Pruess et al., 1999b). Tracer-transport simulations 
were run using the T2R3D code (Wu and Pruess, 2000). The 3-D flow simulation with two million gridblocks were conducted using a parallel-computing version of the TOUGH2 code (Zhang et al., 2001). All the flow model results discussed below represent steady-state conditions, with tracer transported in response to the resulting steady-state flow field.

\section{2-D Flow Model Results and Analyses}

In the following discussion, the realization of fracture permeability field with a correlation length of $1 \mathrm{~m}$ (Realization \#1) is considered the base case. In addition, the upper model boundary for the base-case modeling scenario is prescribed with uniform percolation flux of $5 \mathrm{~mm} / \mathrm{yr}$.

\subsection{Model Results with $1 \mathrm{~m}$ Correlation Length}

Figure 2 shows the distribution of the magnitude of simulated liquid mass flux within the 2-D domain with the base-case scenario. The figure shows that, in this flow scenario, several vertical high-flux channels or discrete flow paths (or weeps) develop. In addition, Figure 2 indicates that about five to ten major pathways seem to be present in the upper layer (above the elevation of $110 \mathrm{~m}$ ) with considerably more being present in the lower layer (owing to the different permeability variability within these two layers). As clearly shown in the figure, the flow is predominantly vertical over the entire model domain, as would be expected because of the high permeability, low capillary forces of the fracture system, as well as no lateral flow conditions posed on the side boundaries.

Figure 3 shows the vertical liquid mass flux along two horizontal lines at different elevations. The first one is located at the depth of $25 \mathrm{~m}$ (Figure 3a); the second one is at the bottom of the model domain (Figure 3b, at $150 \mathrm{~m}$ depth). At both elevations, the figure shows a significant variability in flux, with values ranging from practically $0 \mathrm{~mm} /$ year to almost $30 \mathrm{~mm} /$ year. The 
results indicate the development of some 50 weeps over the 100 m model length —about one water pathway every $2 \mathrm{~m}$. Note that there appear some differences in both locations and values of high fluxes along the two elevations, indicating higher fluxes at certain locations of the lower, bottom boundary (Figure $3 \mathrm{~b}$ ). While the flow patterns change abruptly at a contact between two subunits (here, at a depth of $110 \mathrm{~m}$ ), they appear to remain similar within a given subunit. This suggests that the water flow paths and their characteristics develop within tens of meters from the top of the model or a contact, but they are statistically similar within a subunit over extended vertical distances $(>100 \mathrm{~m})$.

Several sensitivity analyses were performed using different infiltration rates and finer or coarser discretization with the 2-D model. In particular, the flux values of the top boundary condition were varied from 1 to $500 \mathrm{~mm}$ per year. Figure 4 shows the normalized flux plotted against the frequency for five distinct infiltration rates: 1, 5, 25, 100, and $500 \mathrm{~mm} / \mathrm{yr}$. Correlated to normalized fluxes, the flux-frequency distribution for all the infiltration rates are statistically similar. The majority of fluxes are covered by flow paths having low normalized fluxes ranging from zero to two, with the remainder being low- frequency, high normalized fluxes. The maximum flux that occurs in the system is generally about five to six times more than the infiltration flux prescribed at the upper boundary.

A second realization of fracture permeability (Realization \#2) was considered, generated using a different random number but otherwise using the same fracture properties and model domain (with a correlation length of $1 \mathrm{~m}$ ). The permeability distribution is found to be similar to that shown in Figure 1a. For this realization with percolation fluxes of 1, 25, and $500 \mathrm{~mm} / \mathrm{yr}$ imposed at the upper boundary, the frequency plot of normalized flux was found similar to that shown in the first realization (see Figure 4). It therefore appears that these statistical results, 
shown in these figures, could be used in future TSPA analyses of flow focusing at the repository horizon, provided that a correlation length of $1 \mathrm{~m}$ is representative.

\subsection{Model Results with 3 m Correlation Length}

Simulations performed using a $3 \mathrm{~m}$ correlation length for the fracture permeability field (see Figure 1b) are presented below. As expected, the regions of high and low permeability are relatively larger. Individual patches have the size of the correlation length; they occasionally coalesce to form larger patches on the order of three meters. Fracture permeability ranges from about $100 \mathrm{mD}$ to over $100 \mathrm{D}$.

Figure 5 shows the distribution of simulated liquid flux across the 2-D domain with the 5 $\mathrm{mm} /$ year infiltration prescribed on the top. Compared with flow patterns in Figure 2 for the $1 \mathrm{~m}$ correlation length case, Figure 5 shows that a more strongly correlated permeability field leads to fewer but wider discrete, high-flux flow paths or weeps because of the comparatively larger areas with similar high or low permeabilities (Figure 1b), which results in larger upper and lower flow zones.

Figure 6 displays vertical liquid fluxes at elevations of $-25 \mathrm{~m}$ and $-150 \mathrm{~m}$ (bottom), respectively. The figure shows that there are fewer but larger extended regions of low and high liquid flux for this case compared to the $1 \mathrm{~m}$ correlation-length case (Figure 3). The extended regions of high or low flux cover on the order of tens of meters rather than just a few meters (as in the previous case). In addition, comparison of Figures $6 \mathrm{a}$ and $6 \mathrm{~b}$ shows different patterns at the two elevations. This indicates that the large correlation length $(3 \mathrm{~m})$ requires a longer vertical traveling distance to reach the statistically similar flux distributions. In addition, under different infiltration rates at the upper boundary the $3 \mathrm{~m}$ correlation length case also gives a similar normalized flux versus flux-frequency distribution to that of the base case (Figure 4). 


\subsection{Results with Nonuniform Infiltration}

A sensitivity study about the effect of nonuniform, steady infiltration at the upper boundary (the bottom of the PTn with the base-case scenario) is given here with the 1-m correlation length scenario. The case considered is that of water being injected nonuniformly at over $0.25 \mathrm{~m}$ wide sections at every $5 \mathrm{~m}$ interval along the top boundary, with the total amount of injected mass flux the same as that of the $5 \mathrm{~m}$ uniformly distributed infiltration. Thus there are 20 discrete sources at the top of the model over the $100 \mathrm{~m}$ width of the model domain. Figure 7 shows the normalized flux versus frequency for this case at different infiltration rates. Comparison of Figure 7 with Figure 4 shows that results, using uniform and discretely applied, nonuniform infiltration at the top boundary, are similar. This sensitivity analysis indicates that the heterogeneity controls flow, i.e., the non-uniformly applied infiltration, with the 5-m scale, is quickly redistributed to reflect the pattern of the fracture network.

\subsection{Alternative Flow Allocation Scenario}

An additional sensitivity study using the base-case scenario and uniform infiltration was conducted in which a different flow allocation throughout the fracture system was employed. As field evidence suggests that net infiltration at Yucca Mountain is highly variable both spatially and in time because of variations in soil cover and precipitation (Flint et al., 1996), percolation in unsaturated fractures at Yucca Mountain may be episodic and very discrete. The TOUGH2 code was modified to enable simulating this phenomenon of flow convergence or divergence in a scenario that we refer to here as the "all-in-one" (AIO) scenario. The numerical grid and model parameters were modified such that at each intersection, effective permeabilities to the liquid phase and water potentials were evaluated to determine the direction of maximum mass flow occurring. Subsequently, almost all of the available water going through that specific fracture 
element was allocated to these more permeable or "favorite" connections for receiving (inflow) and leaving (outflow) fractures, which was achieved by reducing the effective permeabilities along the remaining, lower mass-flow connections by a factor of $10^{-6}$. This is equivalent to keeping only one inflow and one outflow channel open to each fracture gridblock (while turning off low-permeability, low mass-flow paths) to describe a more discrete nature of fracture flow.

Figure $8 \mathrm{a}$ and $8 \mathrm{~b}$ show the liquid flux as a function of horizontal distance at $25 \mathrm{~m}$ and $150 \mathrm{~m}$ (bottom of model) depths, respectively. Comparison of the two figures shows that the distribution of flux is very different between the depths of $25 \mathrm{~m}$ and $150 \mathrm{~m}$. Comparison with Figures 3 and 8 shows that there are fewer but higher flux "weeps", in particular at the $25 \mathrm{~m}$ depth, in the AIO model than in the previous, base-case scenario. For example, Figure $8 \mathrm{~b}$ presents more than 11 weeps with over $20 \mathrm{~mm} / \mathrm{yr}$ fluxes, while Figure $3 \mathrm{~b}$ shows only one in this high flux range. This is to be expected because the AIO approach is similar to the percolation theory approach that favors flow focusing along high-permeability channels. Figure 9 shows the normalized flux versus frequency for the AIO case. The figure clearly shows that most of the flow paths have very little flux ( $<0.5$ normalized flux $)$, but relatively larger percentage of highflux weeps ( $>4$ normalized flux, Figures 8 versus 3), spaced some $10 \mathrm{~m}$ apart (Figure 8).

\section{2-D Transport Results and Analyses}

Tracer transport analyses with the 2-D model may provide additional insight into flow focusing and discrete paths. Here we discuss some of the transport modeling using the $5 \mathrm{~mm} / \mathrm{yr}$ average infiltration rate on the upper boundary of the 2-D model with both uniformly (base-case) and nonuniformly distributed (20 infiltration blocks) infiltration rates. Steady-state flow fields are generated using a fracture permeability field with a $1 \mathrm{~m}$ correlation length. In addition, the AIO flow scenario is employed for a total of three different cases. A conservative tracer 
(nonsorbing) with a molecular diffusion coefficient of $\mathrm{D}_{\mathrm{m}}=3.2 \times 10^{-11}\left(\mathrm{~m}^{2} / \mathrm{s}\right)$ (for technetium) is introduced with a constant concentration condition at the top model boundary. Under steadystate flow conditions, the tracer is transported into the model domain from the top by advection and diffusion as time starts.

Figures 10a, b, and c show the concentrations in the three model domains after one year. Note that traveling distance should be overpredicted because all matrix blocks are omitted in these simulations, so that retardation resulting from matrix diffusion and sorption are simply neglected. Evaluation of the results in Figure 10 indicates that the base-case tracer transport leads to much larger, diluted plumes and less fingering than for either of the other two cases, which appears to be counterintuitive. A close examination indicates that the lesser degree of fingering in the basecase transport (Figure 10a) is because of relatively more "uniformity" in the focused flow (Figure 3) compared with the other two cases under steady-state flow condition. Note that the transport behavior of the latter two cases is very similar at both one and five years of simulations. The slower tracer migration for the nonuniform boundary condition and AIO cases results from the steady-state liquid saturations in fractures for those two cases being significantly higher than that for the base case. For example, a large fraction of fracture liquid saturations in the two latter cases exceeds $10 \%$, whereas the highest water saturation for the base case is on the order of $1 \%$ in the entire model domain. These higher water saturations along high-flux flow channels provide a large liquid volume to store the tracer mass being transported through the fractures, resulting in smaller diluted tracer plumes or more concentrated transport paths.

\section{3-D Flow Model Results and Analyses}

To examine the impact of flow dimensionality of focusing, a 3-D model was developed. The 3-D model of a $50 \mathrm{~m} \times 50 \mathrm{~m} \times 150 \mathrm{~m}$ domain, as discussed above. Similar to the 2-D model, the 
3-D model uses a 1-m correlation length and has the upper boundary at the bottom of the PTn and the lower boundary at the repository horizon. It covers the same five hydrogeological subunits from TSw31 to TSw35. Different cases were run (with the upper boundary prescribed) with uniform infiltration flux of $1,5,25$, and $100 \mathrm{~mm} /$ year, respectively.

Figure 11 shows the frequency distribution of normalized percolation fluxes along the bottom boundary of the 3-D model domain, i.e., on the repository level. The statistical analyses provide certain insights into 3-D flow-focusing effects, which can be seen by comparing statistical results (Figure 11) from the 3-D model along the model's bottom boundary with those of the 2-D basecase model (e.g., Figure 4). First, Figure 11 shows that peak values of area frequencies correspond to the same normalized flux with four different infiltration conditions. With the 3-D model results, higher infiltration rates result in relatively lower peak percentages of flux-area frequency (i.e., higher infiltration rates lead to a larger percentage of high fluxes or more focusing flow). On the high end of fluxes, the 3-D model results (Figure 11) show slightly higher percentage of high normalized fluxes $(>4)$ than that from the 2-D model. Similar to the 2-D model results (e.g., Figures 4 and 7), the statistics in Figure 11 also indicate that high fluxes (of about five times more than the prescribed infiltration rates) are statistically insignificant and may be ignored in the performance analysis.

Comparison of the 2-D and 3-D model results in Figure 11 shows a significantly different distribution in area frequencies, mainly in low and intermediate normalized flux range (normalized flux less than 1), although they have similar patterns. The most distinctive difference between the two model results is that the 3-D model predicts much higher areafrequency values at low normalized fluxes (less than 0.5 ) than the 2-D model. However, for high normalized fluxes or weeps (of about three to five times more than the average infiltration flux), 
the two models give statistically equivalent frequency distributions in spite of the 3-D modeling resulting in relatively larger frequencies. Due to under-predicting low-flux distributions, as shown in Figure 11, the 2-D model estimates much higher flow focusing for intermediate ranges of normalized fluxes (between one to three times more than the infiltration rates),

Figure 12 displays the frequency distributions of vertical fluxes extracted along four horizontal planes at four different depths $(25 \mathrm{~m}, 100 \mathrm{~m}, 115 \mathrm{~m}$, and $150 \mathrm{~m}$, with an infiltration flux of $5 \mathrm{~mm} / \mathrm{yr}$ specified on the top. In contrast to the corresponding 2-D simulation results, Figure 12 shows that it takes a longer distance to develop flow-focusing paths in the 3-D model than the 2-D model. We also examined 3-D flow patterns along several vertical slices of the 3-D model domain and found that the 3-D vertical high-flux paths are generally shorter (less than 20 m) and show a more tortuous pattern than the 2-D flow paths, as predicted by the 2-D model. This implies that the high-flux paths may not be vertical throughout due to local heterogeneity in fracture permeability fields. Actual weeps may flow freely into or from the third dimension following any lowest flow-resistance path, because of one additional degree of freedom in dimension with a 3-D model. Comparison between the flow patterns revealed by the 2-D and 3D model results in Figure 12 suggests that the 3-D modeling study may be necessary for understanding discrete-fracture flow behavior in a real, 3-D formation.

\section{Application}

The results of the analyses, such as those shown in Figures 4, 7, 9, and 11, can be used to define the flow-focusing factor for subsequent seepage modeling studies and TSPA calculations. In fact, we have completed many more simulations than those in Sections 3, 4 and 5, using different permeability distributions on different 2-D and 3-D models with different gird resolutions, resulting in similar flow patterns to what are summarized in the previous sections. 
Therefore, the similarity in normalized flux-frequency distributions suggests that it be reasonable to define a single distribution that applies to all expected infiltration scenarios. Figure 13 presents a regression curve as an example, along with the $95 \%$ confidence bands that summarize the results of all the simulations for flow at the repository level computed with the 2-D models.

The distribution shown in Figure 13 helps to select a flow-focusing factor to be applied in TSPA seepage calculations. Two important observations can be made from Figure 13: (1) the simulations indicate that flux enhancement due to flow focusing is usually less than 3 and always less than about 6; and (2) there is little spread in the results obtained for the different scenarios considered in this study. Therefore, the results of Figure 13 can be used to provide input parameters on maximum percolation fluxes under different infiltration scenarios for estimating seepage amount into drifts in the TSPA calculations.

\section{Summary and Conclusions}

A series of numerical studies has been conducted to evaluate flow-focusing phenomena in unsaturated fractures at the potential repository horizon at Yucca Mountain. These modeling studies were conducted using both 2-D and 3-D models and considered five different TSw hydrogeological units of Yucca Mountain. The numerical models used high-resolution grids to capture discrete-fracture effects. Fracture parameters used in the simulations were those developed for the UZ flow model, with the exception of fracture permeabilities (which were prescribed using a stochastic approach). Sensitivity studies were performed with various infiltration rates, different correlation lengths of the fracture permeability fields, uniform and nonuniform infiltration-flux boundary conditions, and different flow allocation schemes. 
The modeling studies obtained in this work provide many insights into flow-focusing phenomena and discrete flow paths through unsaturated fractures at Yucca Mountain, including forming of 2-D and 3-D high-flux flow paths, percolation patterns as functions of depths, and impact of statistical parameters and flow conditions. In particular, the graphs showing a statistical function of flux-frequency distributions versus normalized infiltration fluxes can be directly used and incorporated in the TSPA calculations.

This work presents our continual efforts of characterizing flow and transport processes with the UZ system of Yucca Mountain. The study has been focused on the fracture flow behavior from the bottom of the PTn unit to the repository horizon. For a complete understanding of flowfocusing effects on flow and transport through unsaturated rocks in the entire UZ system, more studies may be needed. Further studies are suggested to look at several areas, such as the role played by the PTn unit in transmitting transient infiltration and transient percolation analyses with fracture-matrix interactions.

\section{Acknowledgments}

The authors would like to thank S. Finsterle and D. Hawkes for their careful and critical review of the manuscript. Thanks are also due to S. Finsterle and M. Villavert for their help in this work. We would also like to thank the two anonymous reviewers for their insightful and constructive comments and suggestions to improve the manuscript. This work was supported by the Director, Office of Civilian Radioactive Waste Management, U.S. Department of Energy, through Memorandum Purchase Order EA9013MC5X between Bechtel SAIC Company, LLC and the Ernest Orlando Lawrence Berkeley National Laboratory (Berkeley Lab). The support is 
provided to Berkeley Lab through the U.S. Department of Energy Contract No. DE-AC0376 SF00098.

\section{REFERENCES}

Ahlers, C.F. and Liu, H.H., 2000. Calibrated Properties Model, MDL-NBS-HS-000003 REV00. CRWMS M\&O, Las Vegas, Nevada.

Birkholzer, J., Li, G., Tsang, C.-F., and Tsang, Y., 1999. Modeling studies and analysis of seepage into drifts at Yucca Mountain. Journal of Contaminant Hydrology 38(1-3): 281322.

Bodvarsson, G. S., Ahlers, C. F., Cushey, M., Dove, F. H., Finsterle, S.A., Haukwa, C. B., Hinds, J., Ho, C. K., Houseworth, J., Hu, Q., Liu, H.H., Pendleton, M., Sonnenthal, E. L., Unger, A. J., Wang, J. S. Y.,Wilson, M., and Wu, Y.-S., 2000, Unsaturated zone flow and transport model process model report, TDR-NBS-HS-000002, REV00. CRWMS M\&O, Las Vegas, Nevada.

Deutsch, C.V. and Journel, A.G., 1992. GSLIB Geostatistical Software Library and User's Guide. Oxford University Press, New York, New York.

Fabryka-Martin, J. T.; Dixon, P.R.; Levy, S.; Liu, B.; Turin, H.J.; and Wolfsberg, A.V., 1996. Systematic Sampling for Chlorine-36 in the Exploratory Studies Facility. LA-CST-TIP96-001, Milestone 3783AD, Los Alamos National Laboratory, Los Alamos, New Mexico.

Finsterle, S., 2000. Using the continuum approach to model unsaturated flow in fractured rock. Water Resources Research, 36(8): 2055-2066. 
Finsterle, S., Ahlers, C.F., and Trautz, R.C., 2000. Seepage Calibration Model and Seepage Testing Data, MDL-NBS-HS-000004 REV01. CRWMS M\&O, Las Vegas, Nevada.

Flint, A. L., Hevesi, J. A. and Flint, E. L., 1996. Conceptual and Numerical Model of infiltration for the Yucca Mountain Area, Nevada, U. S. Geological Survey, Water-Resources Investigation Report-96. U.S. Geological Survey, Denver, Colorado.

Flint, L. E., 1998. Characterization of hydrogeologic units using matrix properties, Yucca Mountain, Nevada, U.S. Geological Survey Water-Resources Investigations Report 974243. U.S. Geological Survey, Denver, Colorado.

Geller, J.T. and Pruess, K., 1995. On water infiltration in rough-walled fractures. Proceedings of the Sixth Annual International High-Level Radioactive Waste Management Conference. American Nuclear Society, La Grange Park, Illinois, pp. 23-25.

Kwicklis, E. and Healey, R.W., 1993. Numerical investigation of steady liquid water flow in a variably saturated fracture network. Water Resources Research, 29(12): 4091-4102.

Liu, H. H., Ahlers C. F., and Cushy M., 2000, Analysis of hydrologic properties, ANL-NBS-HS000002, REV00. CRWMS M\&O, Las Vegas, Nevada.

Pruess, K.A., 1999. Mechanistic model for water seepage through thick unsaturated zones of fractured rocks of low permeability. Water Resources Research, 35(4): 1039-1052.

Pruess, K.; Faybishenko, B. and Bodvarsson, G.S., 1999a. Alternative concepts and approaches for modeling flow and transport in thick unsaturated zones of fractured rocks. Journal of Contaminant Hydrology, 38 (1-3): 281-322.

Pruess K., Oldenburg, C., and Moridis, G., 1999b. TOUGH2 User's Guide, Version 2.0. Report LBNL-43134, Lawrence Berkeley National Laboratory, Berkeley, California. 
Rasmussen, T., 1987. Computer simulation model for steady fluid flow and solute transport through three-dimensional networks of variably saturated, discrete fractures. In: Evans, D., and T. Nicholson (Eds.), Flow and Transport through Unsaturated Fractured Rock, American Geophysical Union, Geophysical Monograph 43: 107-114.

Su, G.W.; Geller, J.T.; Pruess, K. and Wen, F., 1999. Experimental studies of water seepage and intermittent flow in unsaturated, rough-walled fractures. Water Resources Research, 35(4): 1019-1037

Tokunaga, T.K. and Wan, J., 1997. Water film flow along surfaces of porous rock. Water Resources Research, 33 (6): 1287-1295.

van Genuchten, M. Th., 1980. A Closed-Form Equation for Predicting the Hydraulic Conductivity of Unsaturated Soils, Soil Sci. Soc. Amer. J., 44(5), 892-898.

Wang, J.S.Y., Trautz, R.C., Cook, P.J., Finsterle, S., James, A.L., Birkholzer J., and Ahlers, C.F., 1998. Testing and Modeling of Seepage into Drift: Input of Exploratory Study of Facility Seepage Test Results to Unsaturated Zone Models. Yucca Mountain Project Level 4 Milestone SP33PLM4, Lawrence Berkeley National Laboratory, Berkeley, California.

Wu, Y.S. and Pruess K., 2000. Numerical Simulation of Non-Isothermal Multiphase Tracer Transport in Heterogeneous Fractured Porous Media, Advance in Water Resources, 23, 699-723.

Wu, Y.S., Haukwa, C., and Bodvarsson, G.S., 1999. A site-scale model for fluid and heat flow in the unsaturated zone of Yucca Mountain, Nevada. Journal of Contaminant Hydrology, 38 (1-3): 185-215.

Zhang K., Wu, Y.-S., Ding, C., Pruess, K., and Elmroth, E., 2001, Parallel computing techniques for large-scale reservoir simulation of multicomponent and multiphase fluid flow. Paper 
SPE 66343, Proceedings of the 2001 SPE Reservoir Simulation Symposium, Houston, Texas.

Zimmermann, R.W. and Bodvarsson, G.S., 1996. Effective transmissivity in two-dimensional fracture networks, Int. J. Rock Mech. Min. Sci. 33(4): 433-438. 


\section{LIST OF FIGURES}

Figure 1. Spatially correlated fracture permeability fields $\left[\log \left(\mathrm{k}\left(\mathrm{m}^{2}\right)\right)\right]$ used in the model studies: (a) $1 \mathrm{~m}$ correlation length; (b) $3 \mathrm{~m}$ correlation length.

Figure 2. Distribution of flux magnitude within the 2-D model domain, simulated using the base-case scenario with $1 \mathrm{~m}$ correlation length, showing formation of several high-flux flow paths.

Figure 3. Distribution of vertical fluxes within the 2-D model domain, simulated using the basecase scenario with $1 \mathrm{~m}$ correlation length, (a) at a depth of $25 \mathrm{~m}$ and (b) at the bottom.

Figure 4. Frequency distribution of simulated fluxes at different infiltration rates within the 2-D model domain, simulated using the base-case scenario with $1 \mathrm{~m}$ correlation length.

Figure 5. Distribution of flux magnitude within the 2-D model domain, simulated using a $3 \mathrm{~m}$ correlation-length case, indicating forming large high- and low-flux flow paths.

Figure 6. Distribution of vertical fluxes within the 2-D model domain, simulated with the $3 \mathrm{~m}$ correlation length at (a) a depth of $25 \mathrm{~m}$ and (b) the bottom.

Figure 7. Frequency distribution of simulated fluxes at different elevations with $5 \mathrm{~m}$ pulse different infiltration, simulated with $1 \mathrm{~m}$ correlation length.

Figure 8. Distribution of vertical fluxes within the 2-D model domain for the AIO Scenario.

Figure 9. Frequency distribution of saturated fluxes at different elevations for the AIO Scenario.

Figure 10. Tracer migration after one year for (a) the basecase, (b) the nonuniform infiltration case, and (c) the AIO Case. 
Figure 11.Comparison of frequency distribution of 3-D model simulated fluxes at different elevations of the 3-F model domain, with $5 \mathrm{~mm} /$ year infiltration rate.

Figure 12. Frequency distribution of 3-D model simulated fluxes at the bottom boundary with different infiltration rates and comparison with the 2-D model results.

Figure 13. Cumulative flux distribution and range as functions of percolation flux for the bottom of the model domain, averaged over all simulations

\section{LIST OF TABLES}

Table 1. Fracture properties used in the model studies ${ }^{*}$ (Ahlers and Liu, 2000) 
(a)

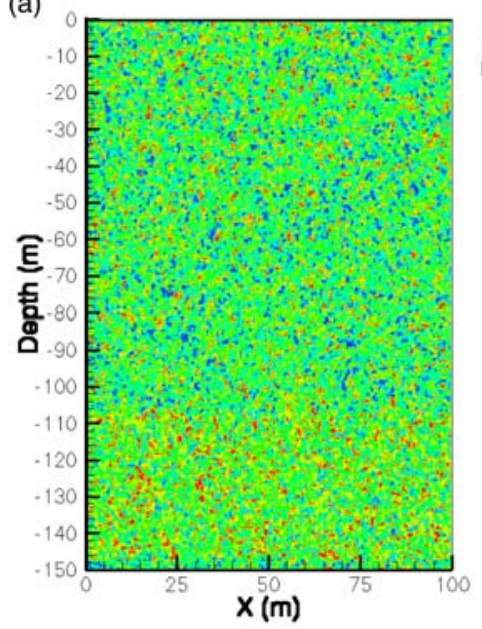

(b)

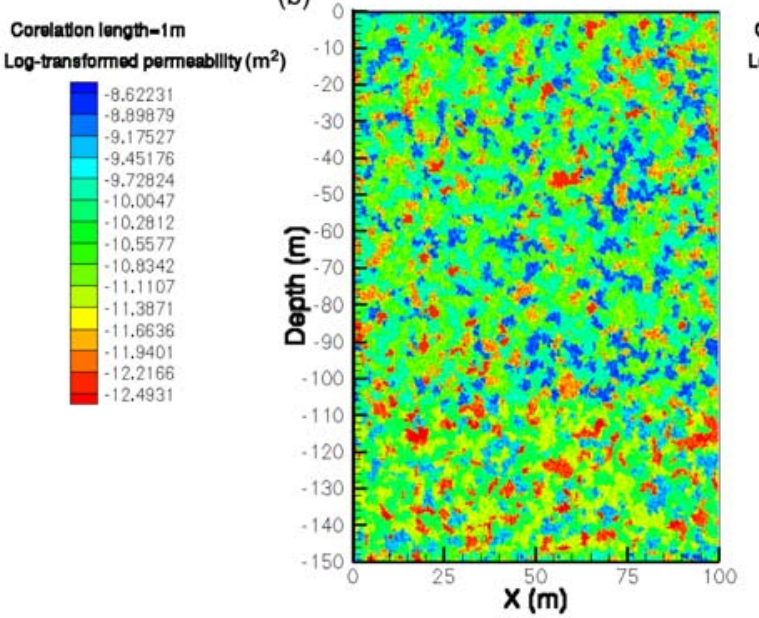

Corelation length-3m

Log-transformed permeabillty $\left(\mathrm{m}^{2}\right)$

-8.62231
-8.89879

$-8.89879$

-9.17527
-9.45176

-9.72824
-10.0047

$-10.2812$

$-10.5577$

-10.8342
-11.1107

-11.1107
-11.3971

-11.6636
-11.9401

-11.9401
-12.2166
-12.4931

$-12.4931$

Figure 1 


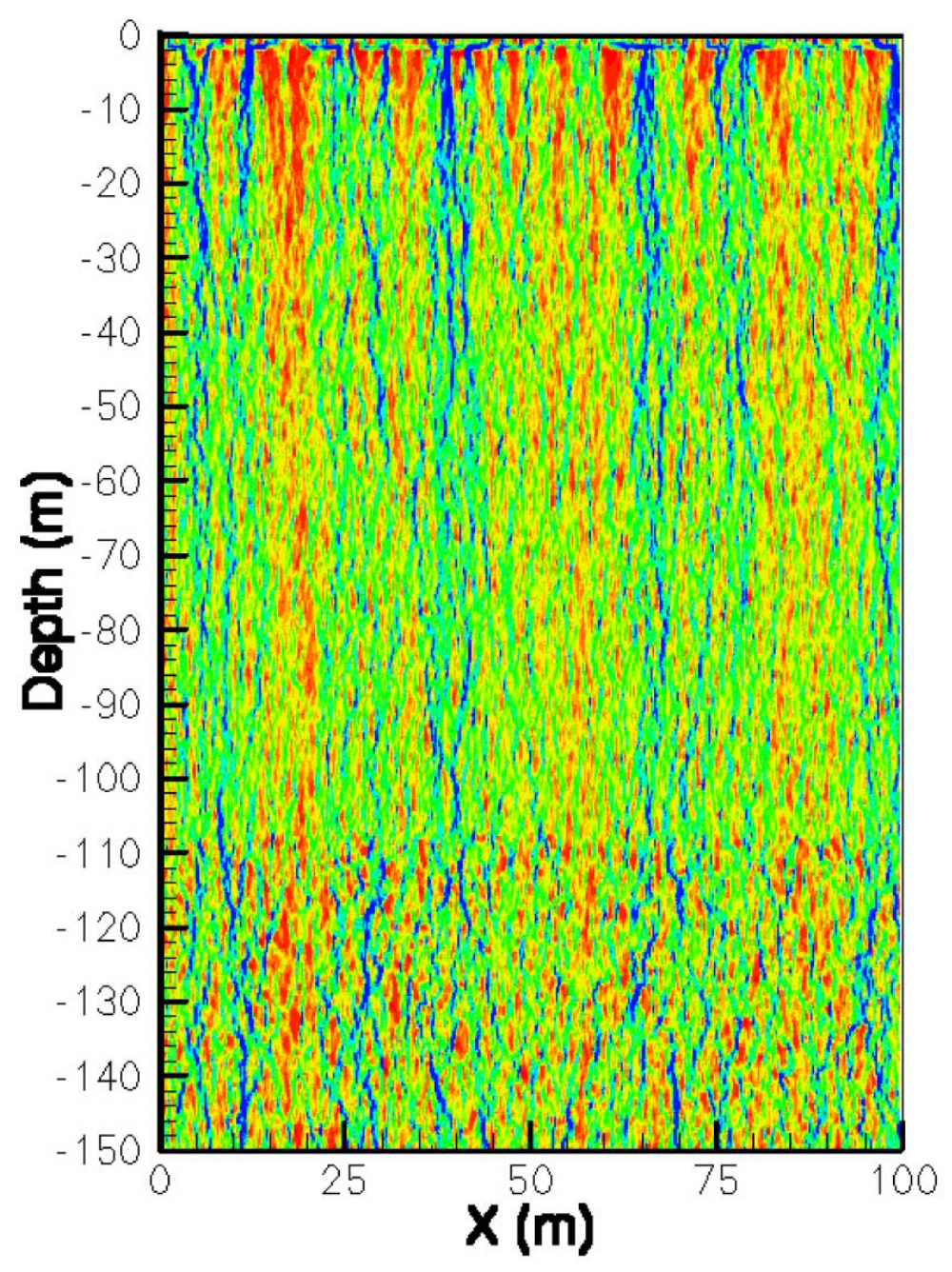

\section{Corelation length $=1 \mathrm{~m}$ Total Flux (kg/m²/s)}

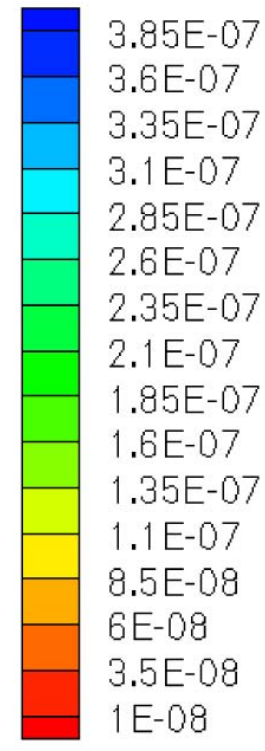

Figure 2 

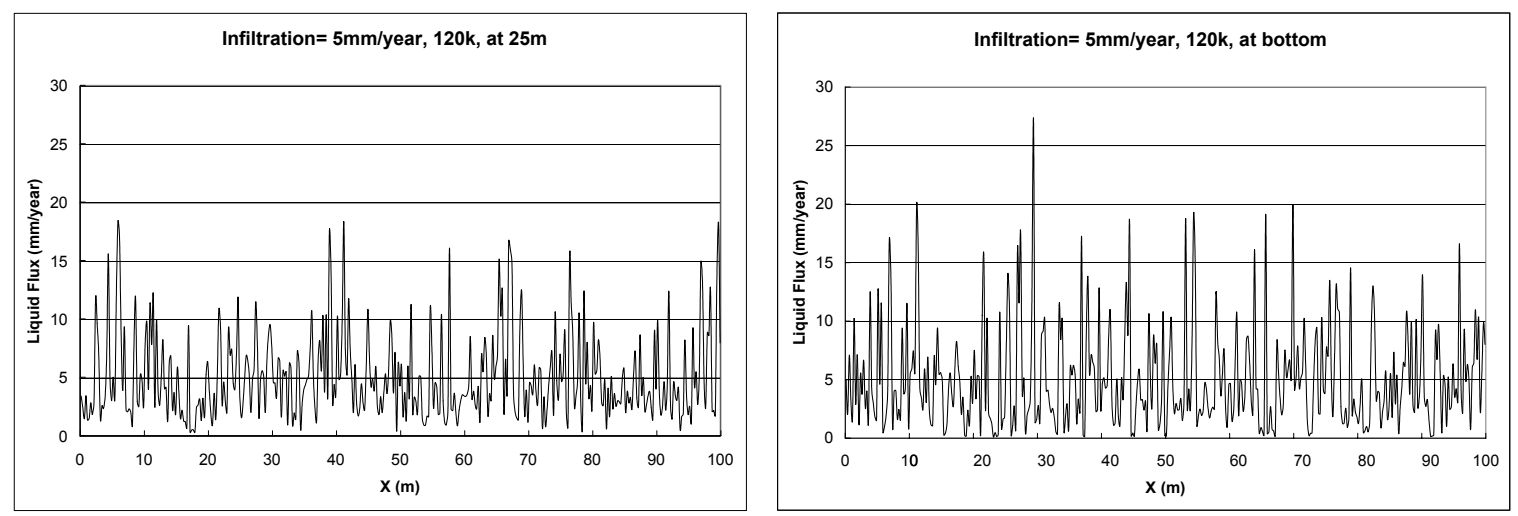

(a)

(b)

Figure 3 


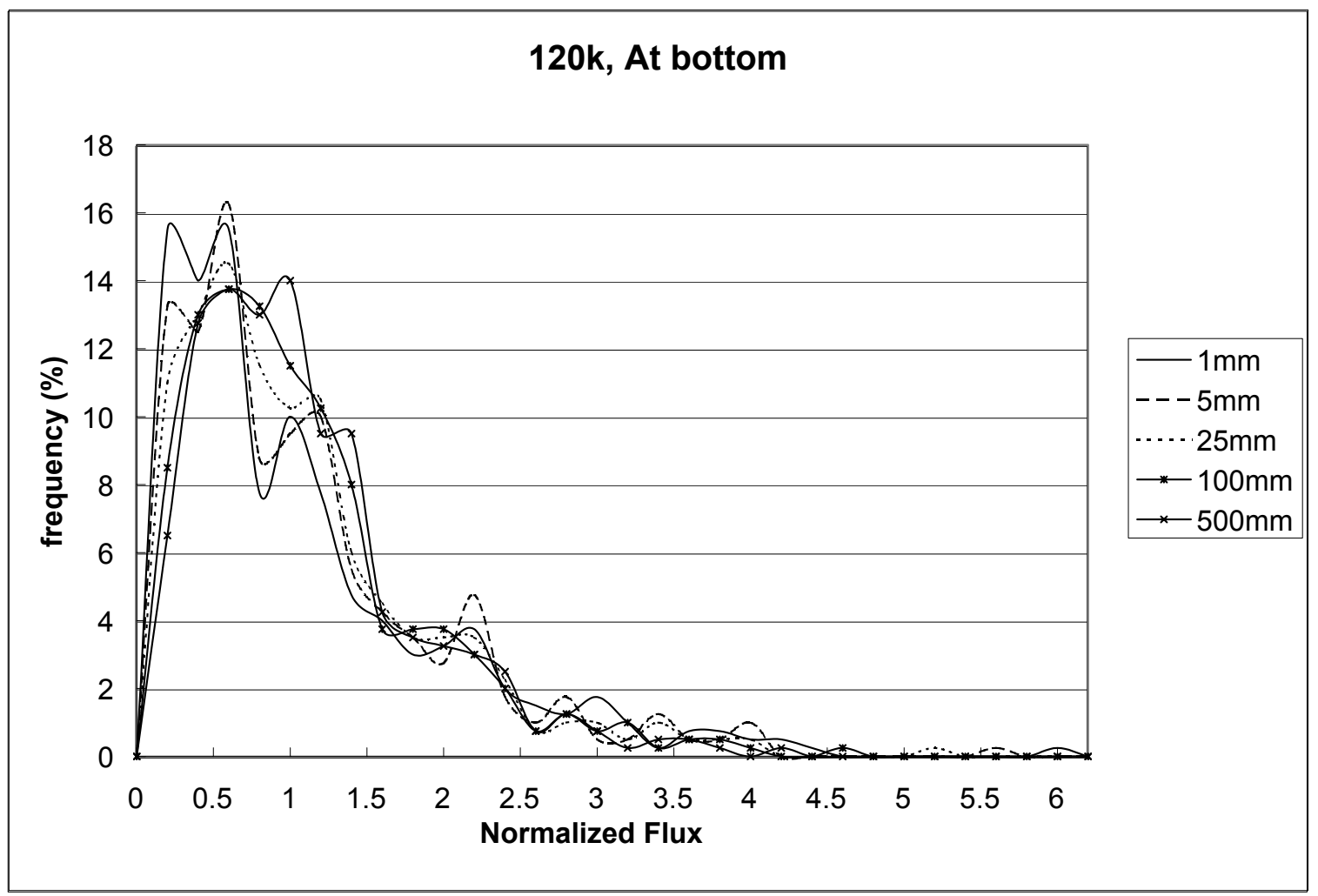

Figure 4 


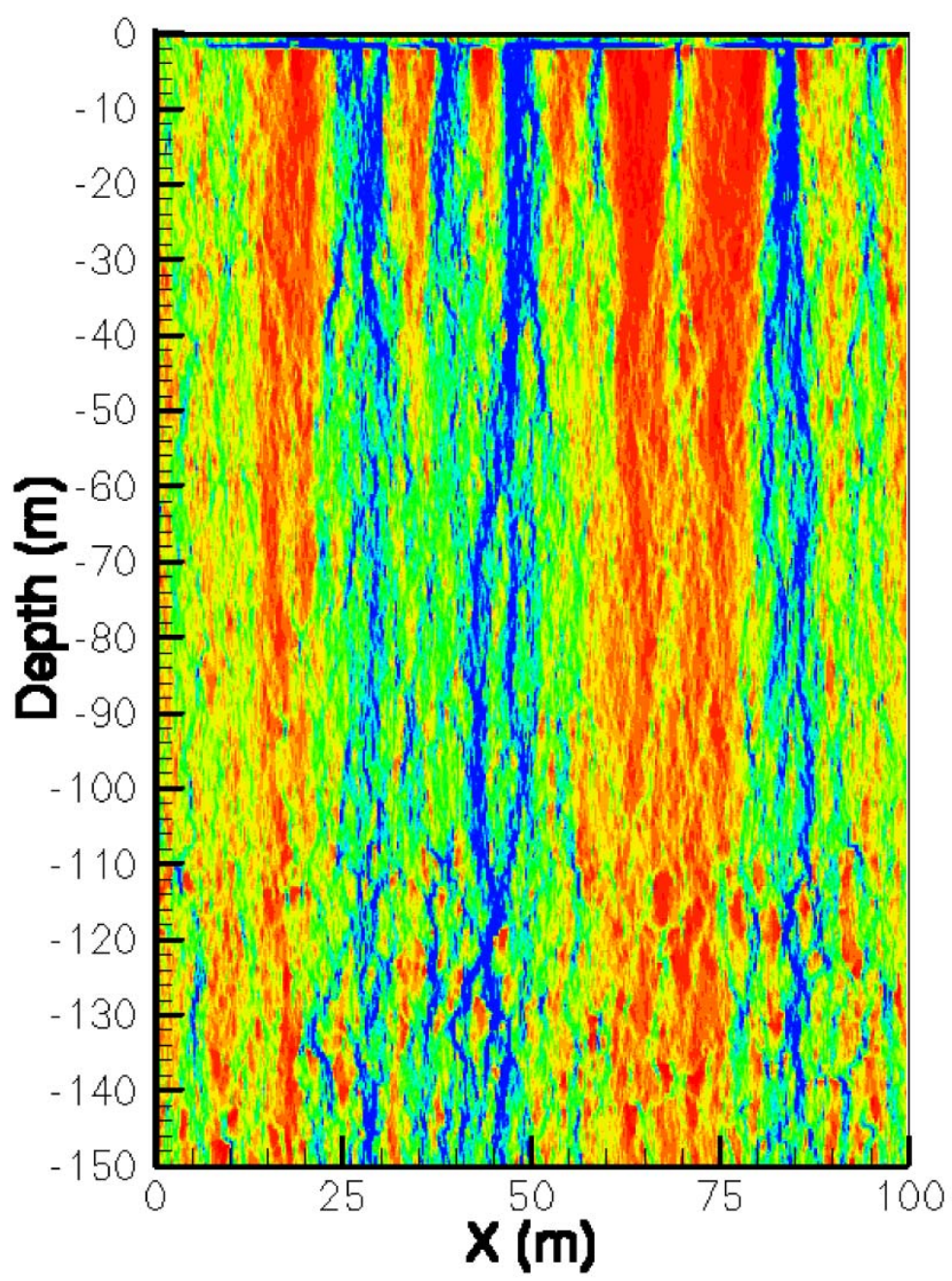

Corelation length $=3 \mathrm{~m}$ Infiltration $=5 \mathrm{~mm} /$ year Total Flux $\left(\mathrm{kg} / \mathrm{m}^{2} / \mathrm{s}\right)$

\begin{tabular}{|l|}
\hline $3.85 \mathrm{E}-07$ \\
$3.6 \mathrm{E}-07$ \\
$3.35 \mathrm{E}-07$ \\
$3.1 \mathrm{E}-07$ \\
$2.85 \mathrm{E}-07$ \\
$2.6 \mathrm{E}-07$ \\
$2.35 \mathrm{E}-07$ \\
$2.1 \mathrm{E}-07$ \\
$1.85 \mathrm{E}-07$ \\
$1.6 \mathrm{E}-07$ \\
$1.35 \mathrm{E}-07$ \\
$1.1 \mathrm{E}-07$ \\
$8.5 \mathrm{E}-08$ \\
$6 \mathrm{E}-08$ \\
$3.5 \mathrm{E}-08$ \\
\hline $1 \mathrm{E}-08$
\end{tabular}

Figure 5 


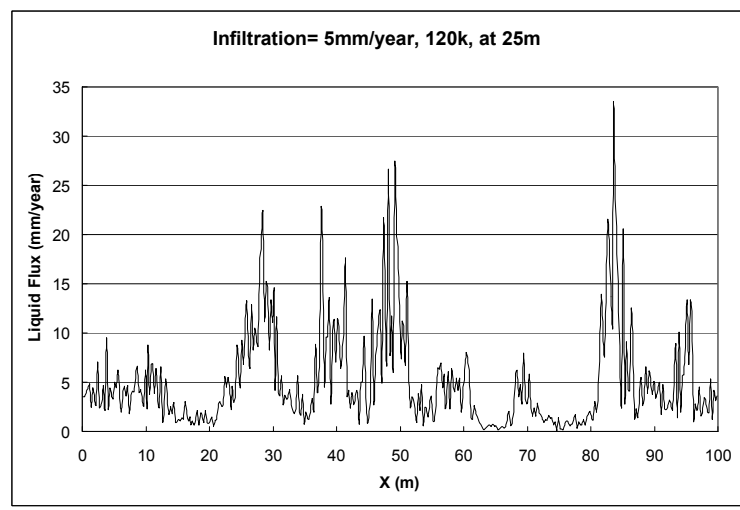

(a)

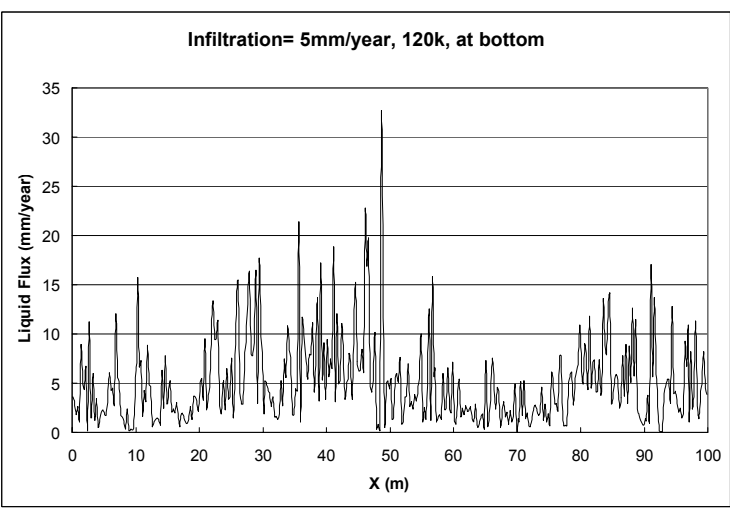

(b)

Figure 6 


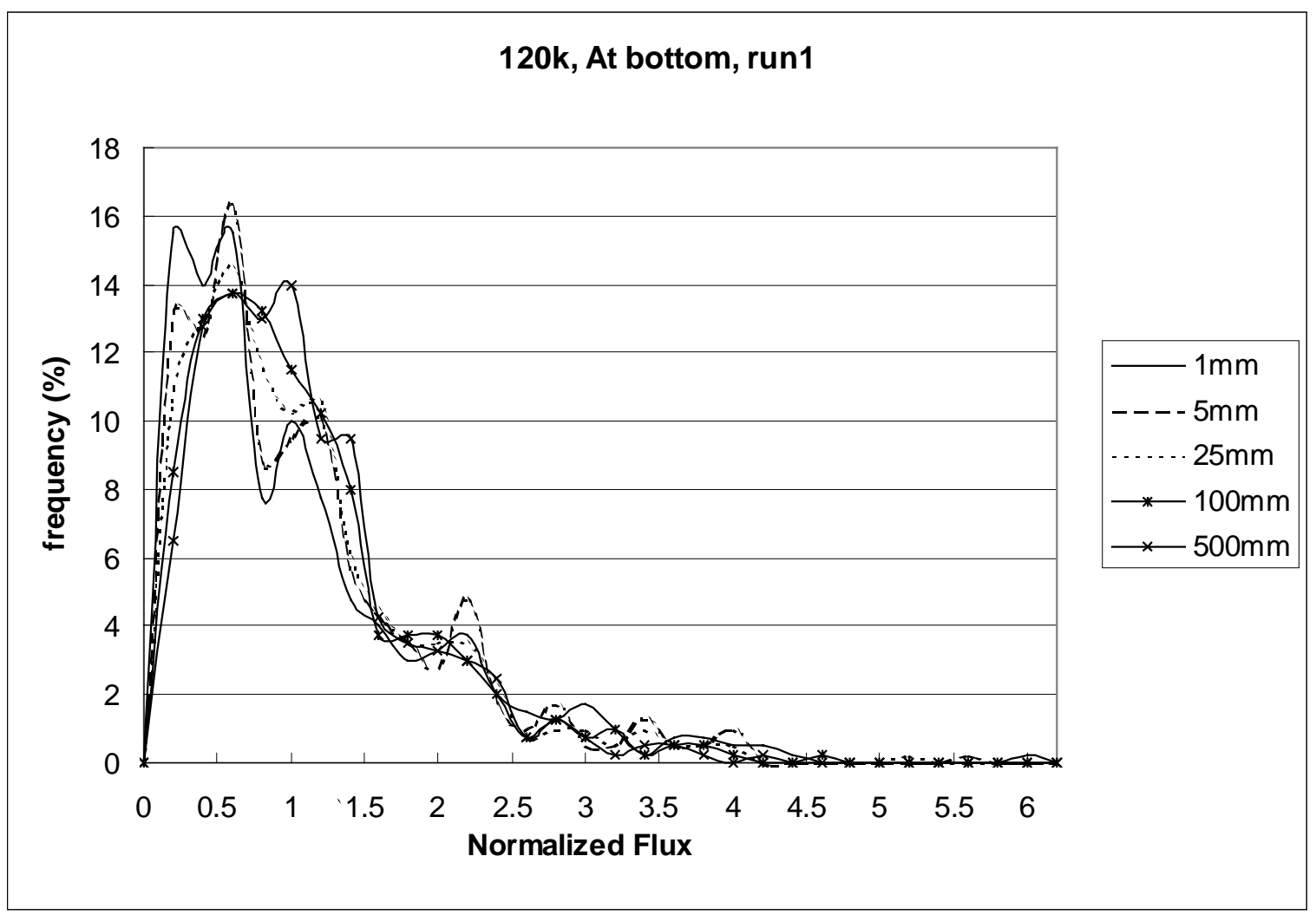

Figure 7 


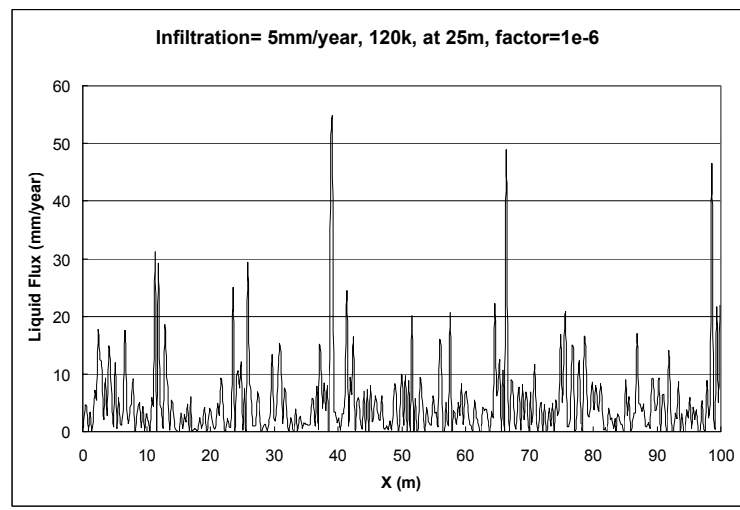

(a)

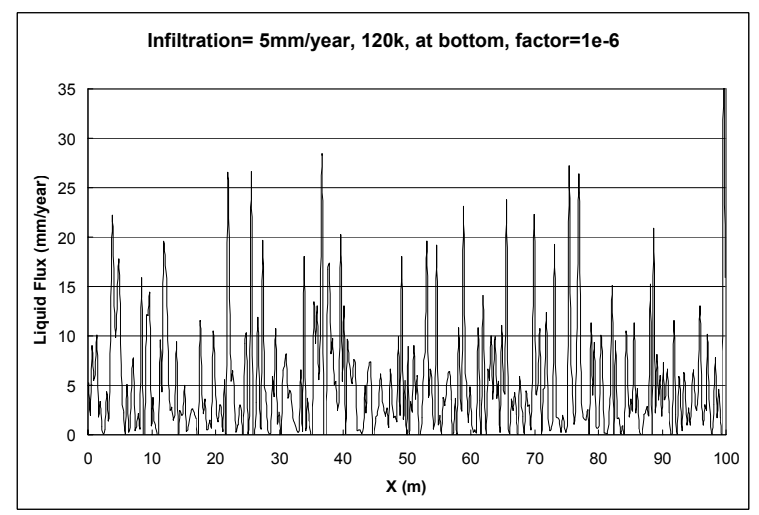

(b)

Figure 8 


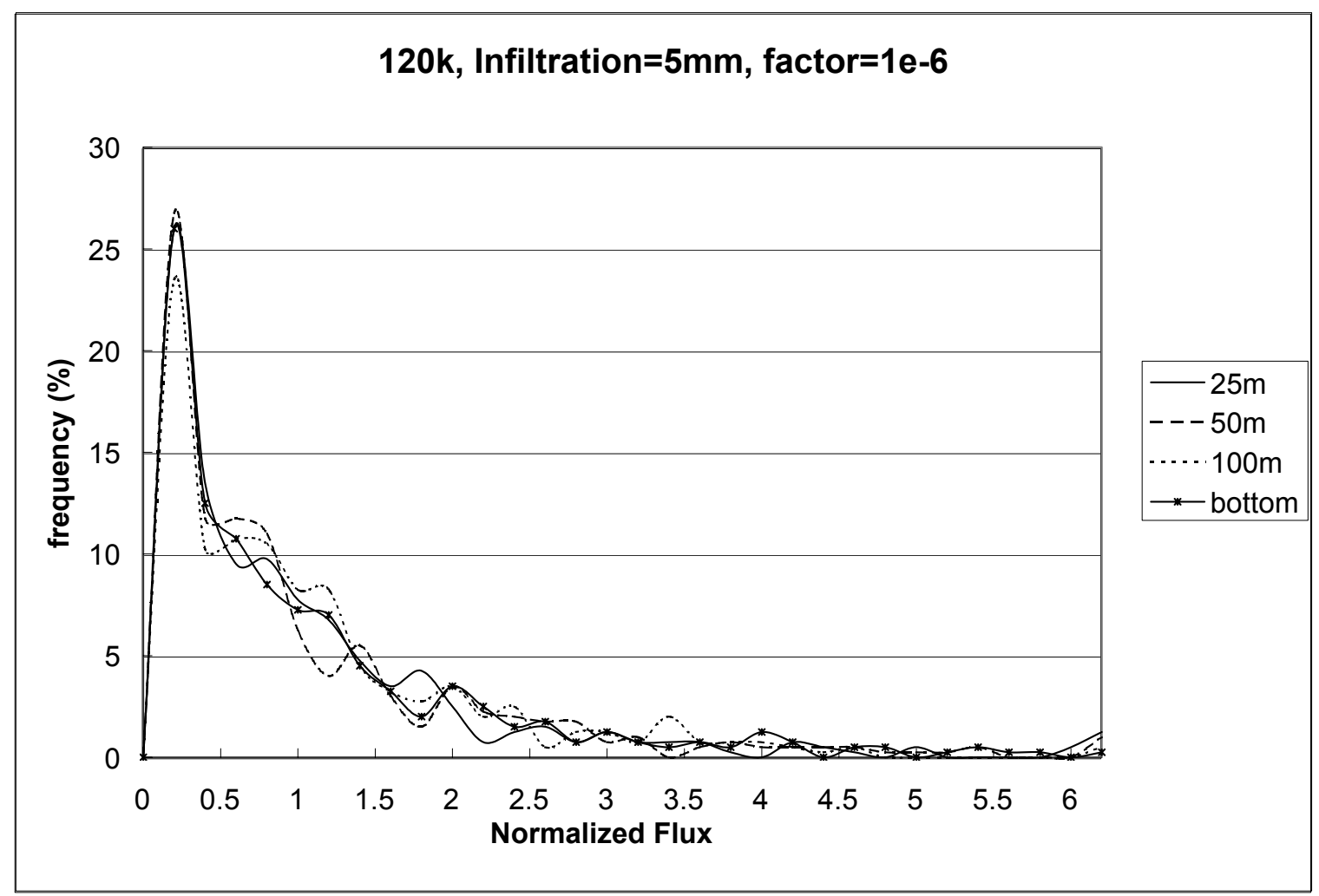

Figure 9 
(a)

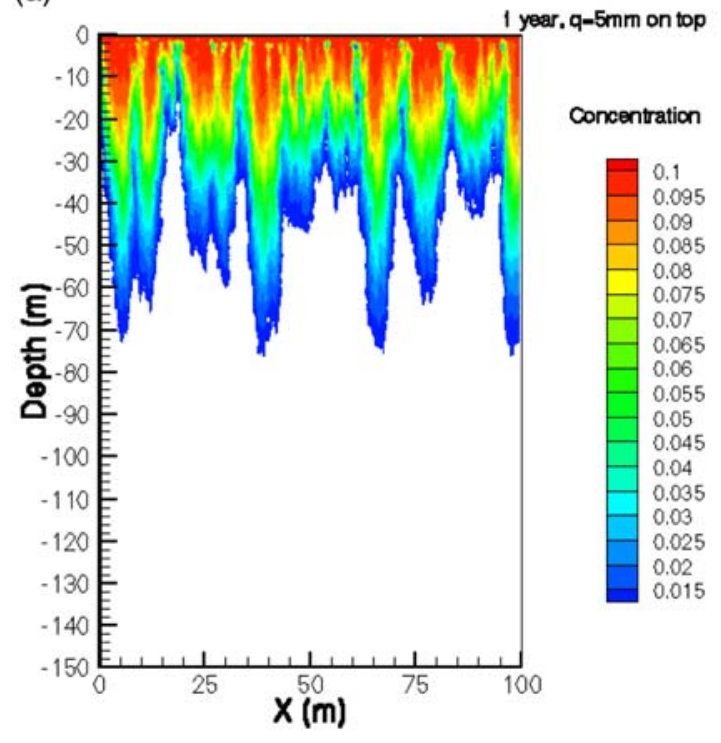

(b)

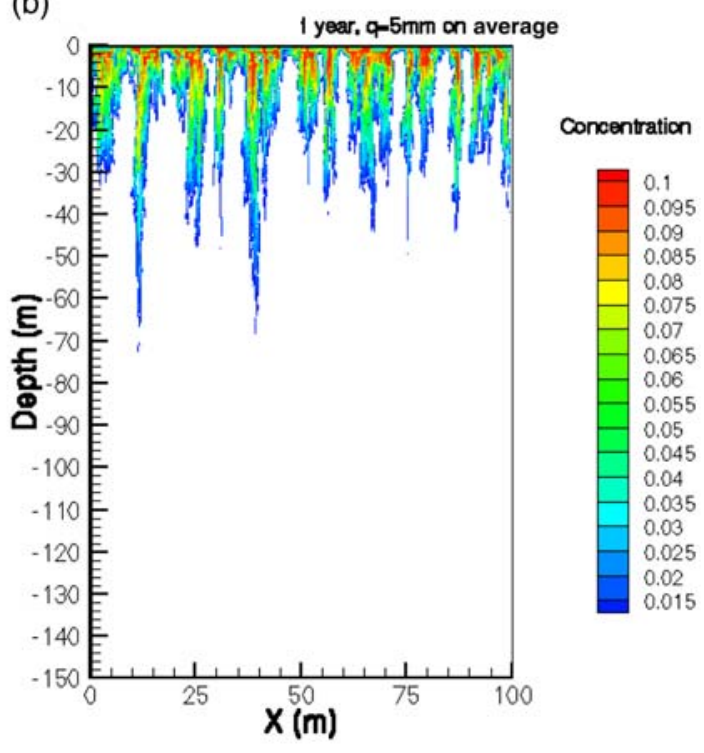

(c)

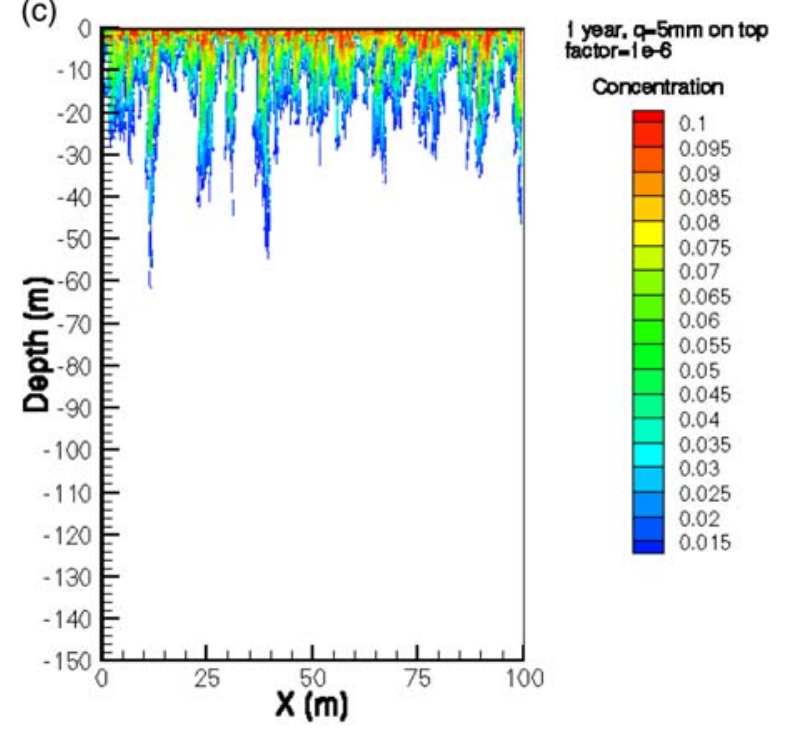

Figure 10 


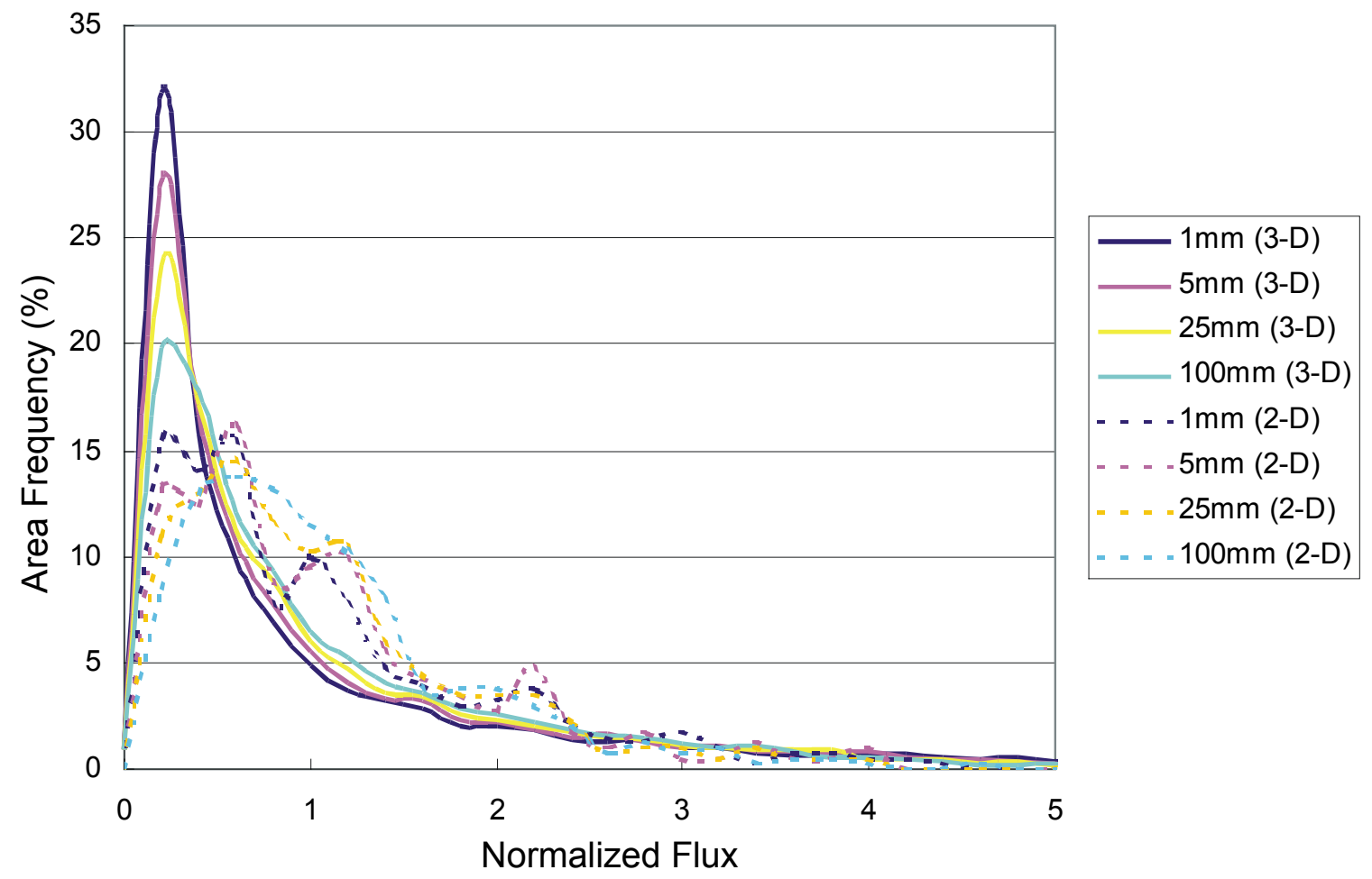

Figure 11 


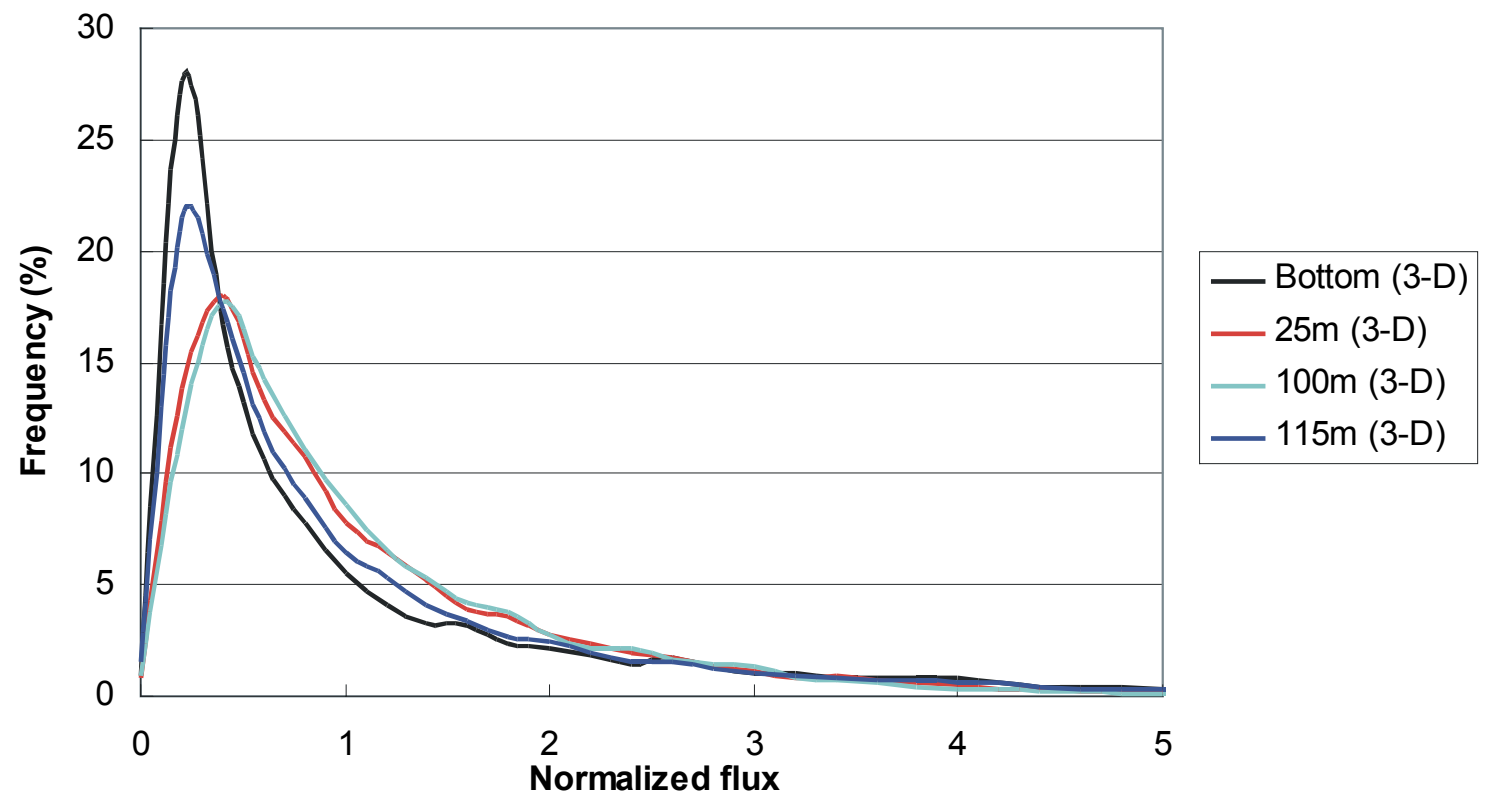

Figure 12 


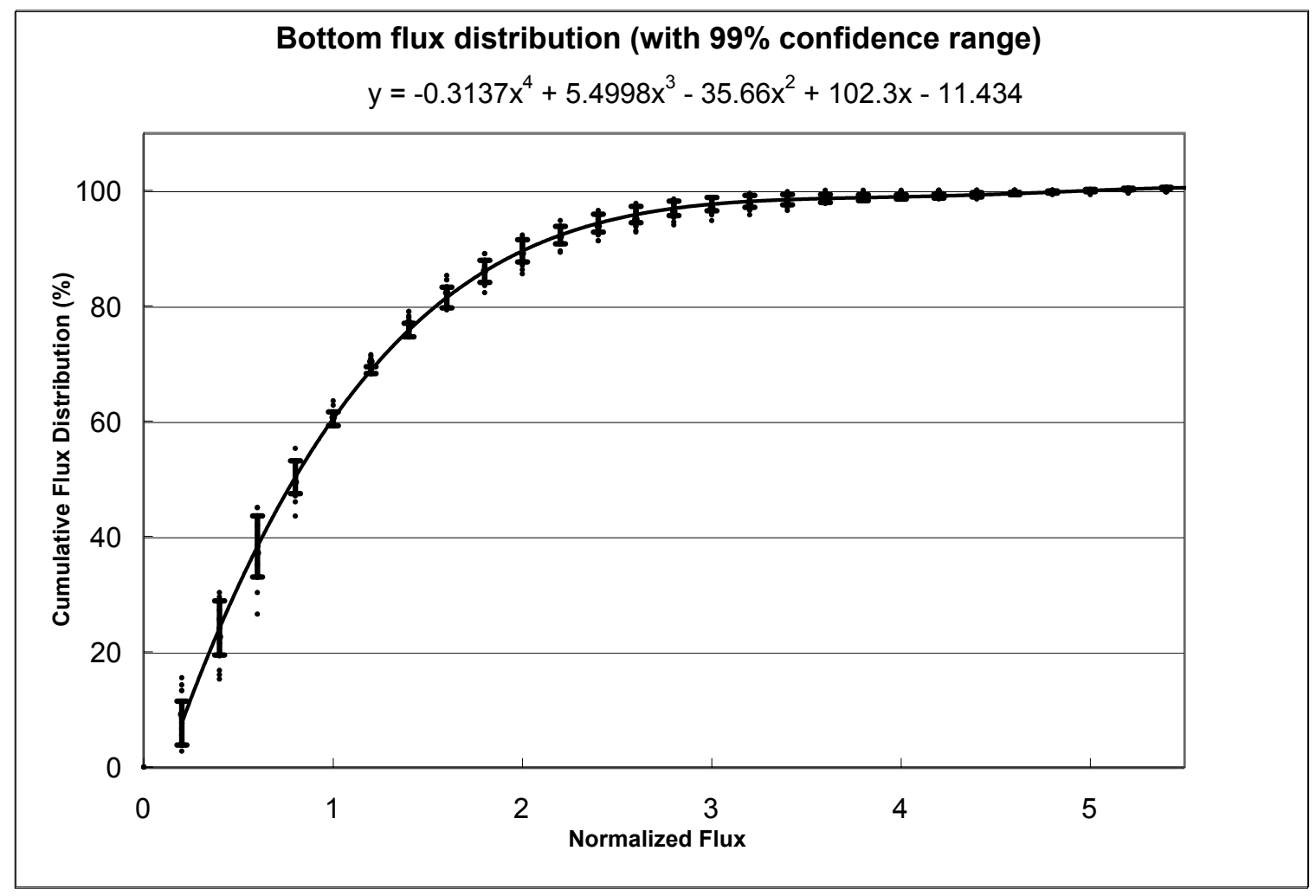

Figure 13 
Table 1. Fracture properties used in the model studies ${ }^{*}$ (Ahlers and Liu, 2000).

\begin{tabular}{|c|c|c|c|c|c|c|}
\hline \multirow{2}{*}{ Model Layer } & \multicolumn{2}{|c|}{$\begin{array}{c}\text { permeability } \\
\left(\mathbf{m}^{2}\right)\end{array}$} & $\begin{array}{c}\alpha_{F} \\
(\mathbf{1} / \mathbf{P a})\end{array}$ & $\begin{array}{c}\boldsymbol{m}_{\boldsymbol{F}} \\
(-)\end{array}$ & $\begin{array}{c}\phi_{F} \\
(-)\end{array}$ & $\begin{array}{c}\boldsymbol{S}_{r f} \\
(-)\end{array}$ \\
\cline { 2 - 7 } & $\boldsymbol{k}_{F}$ & $\sigma_{\log \left(k_{F}\right)}$ & & & & \\
\hline Tsw31 & $3.21 \mathrm{E}-11$ & -- & $2.49 \mathrm{E}-4$ & 0.566 & $5.5 \mathrm{E}-3$ & 0.01 \\
\hline Tsw32 & $3.56 \mathrm{E}-11$ & 0.658 & $1.27 \mathrm{E}-3$ & 0.608 & $9.5 \mathrm{E}-3$ & 0.01 \\
\hline Tsw33 & $3.86 \mathrm{E}-11$ & 0.612 & $1.46 \mathrm{E}-3$ & 0.608 & $6.6 \mathrm{E}-3$ & 0.01 \\
\hline Tsw34 & $1.70 \mathrm{E}-11$ & 0.546 & $5.16 \mathrm{E}-4$ & 0.608 & $1.0 \mathrm{E}-2$ & 0.01 \\
\hline Tsw35 & $4.51 \mathrm{E}-11$ & 0.644 & $7.39 \mathrm{E}-4$ & 0.611 & $1.2 \mathrm{E}-2$ & 0.01 \\
\hline
\end{tabular}

* In the table, $k_{F}$ is saturated fracture continuum permeability, $\sigma_{\log \left(k_{F}\right)}$ is standard deviation of $\log \left(k_{F}\right), \alpha_{F}$ is van Genuchten's parameter (van Genuchten, 1980) of capillary pressure for fracture, $m_{F}$ is van Genuchten's parameter of fracture retention curves, $\phi_{F}$ is fracture porosity, and $S_{r f}$ is residual liquid saturation in fracture. 